\title{
A Large Sample Epidemiological Survey of Severe Mental Disorders: Current Status and Prospects
}

\section{Zheng Fuhao}

Fujian Provincial Hospital, Fujian Medical University

Yawen Lin

Fujian Medical University

Qingfei Wei

Fujian Medical University

Zhaonan Zeng

Fujian Provincial Hospital, Fujian Medical University

\section{Duanhua Xiong}

Fuzhou Neuropsychiatric Hospital

Siying Wu ( $\nabla$ fmuwsy@163.com )

Fujian Medical University

\section{Research Article}

Keywords: Severe mental disorders, Epidemiology, Disease management

Posted Date: September 29th, 2021

DOI: https://doi.org/10.21203/rs.3.rs-890372/v1

License: (c) (1) This work is licensed under a Creative Commons Attribution 4.0 International License.

Read Full License 


\section{Abstract}

Objective: To investigate the prevalence, distribution characteristics, medication status, and management status of patients with severe mental disorders (SMD) in Fuzhou. The medication status and management status were compared between patients in urban and non-urban areas to provide scientific evidence for improving SMD prevention, control, and treatment in primary health care institutions.

Methods: Data (case types, demographic data, distribution data, medication status, and management status, etc.) of 30,362 SMD patients in 12 districts, counties, and prefectures in the urban and non-urban areas of Fuzhou City were collected From March 2018 to September 2018. Three distributions were used to describe the epidemiological characteristics of SMD. Linear trend chi-square test was used to illustrate the relationship between the prevalence of SMD and monthly changes. $\chi 2$ test method was used to compare the severity in urban and non-urban areas (qualitative data of SMD patients).

Results: A total of 30,362 registered SMD patients were identified in Fuzhou City (prevalence rate, $4.17 \%$ ), of which schizophrenia accounted for the highest number $(26204,86.31 \%)$, and paranoid psychosis had the least number (47, 0.15\%). Moreover, most SMD patients were aged 18 (inclusive)-44 years old $(45.38 \%)$. Most patients were farmers $(30.23 \%)$, had a primary school and below education level (54.17\%), were poor, with most below the poverty line standard (55.35\%). The time-point prevalence of SMD was highest in Minqing County (5.29\%o) and lowest in Mawei District (3.80\%o). The prevalence rates of SMD were significantly different among various regions in Fuzhou $(P<0.05)$. There was a linear trend between the month and SMD prevalence, with a statistically significant difference $(P<0.05)$. A total of $22,989(75.72 \%)$ of the patients were taking medications, and only $17,509(57.67 \%)$ were taking medications regularly. Moreover, the rate of taking medications and regular-taking rates were higher in urban areas than in non-urban areas (Pख0.05). A total of 3065 patients were under management $(10.09 \%)$. The management rate was higher in the urban areas than in the non-urban areas $(P<0.05)$.

Conclusion: Schizophrenia needs comprehensive prevention and control in Fuzhou. The management of severe mental disorders should focus on poor groups with low educational backgrounds. Drug usage and management are better in urban areas than in non-urban areas, and thus management should be enhanced in non-urban areas. The medication management and case management of patients with severe mental disorders in Fuzhou need further improvements.

\section{Research Background}

The fast-paced living lifestyle has gradually increased the physical and psychological problems and mental stress of Chinese people due to the rapid progress of economic modernization and urban economy. Furthermore, the incidences of mental illness and other problems have significantly increased ${ }^{1]}$. Severe Mental Disorder (SMD) is a group of mental illnesses with symptoms of mental illness and severely impaired daily social life. SMD includes severe schizophrenia and paranoid mental illness, schizoaffective psychosis, mental disorders caused by epilepsy, and mental retardation (mental 
disorders) ${ }^{2]}$. The global burden of mental disorders was $7 \%$ in 2016 , and SMD threatens more than $4 \%$ of adults worldwide. China has 5.81 million patients with SMD, and the overall average prevalence has increased to $17.5 \%\left[{ }^{3]}\right.$ based on the Bureau of Disease Control and Prevention of the National Health Commission. The average mortality rate of SMD patients is nearly 2-3 times higher than that of the general population, indicating that the mortality rate pattern occurs in both high- and low-income patients $\left[{ }^{4]}\right.$. SMD are common in daily lives and are characterized by mood disorders, conscious dysfunction, and cognitive system dysfunction. Most SMD patients require long-term treatment and nursing, which greatly affects the normal quality of life and social productivity among the patients and their family members $\left[{ }^{[5]}\right.$.

There are more new SMD cases each year, with a higher probability of recurrence and disability. Drug therapy is a crucial treatment for SMD patients regardless of acute illness or long-term management[6]. Ensuring patients' adherence to treatment is also essential for successful mental health management ${ }^{7]}$. Several studies have shown that the chance of SMD recurrence is significantly reduced when patients take drugs for a long time ${ }^{8]}$. Drug non-compliance can lead to serious clinical problems. Various studies have found that the compliance with the use of antipsychotic drugs is very low, as low as $20 \%\left[{ }^{9]}\right.$. Previous research has shown various factors, such as patient-related, drug-related, disease-related, and external environmental factors, including age, 20-year-old insight, educational status, drug quantity, drug side effects, psychotic symptoms, social support, and treatment combinations, affect the compliance of using related medications $\left[{ }^{10]}\right.$.

This study assessed the prevalence, distribution characteristics, medication status, and management status of SMD patients in Fuzhou by comparing the medication status and management status in urban and non-urban areas.

\section{Objects And Methods}

\subsection{Source of information}

The number of cases, general conditions, medications, and management status of SMD patients in the counties (cities) and prefectures in Fuzhou City were obtained from March 2018 to September 2018from the disease information system. The data (clinical disease classification, demographic data, regional distribution, time distribution, treatment status, and management status of patients with severe mental disorders) were mainly from six urban areas in Fuzhou City (Gulou District, Jin'an District, Taijiang District, Cangshan District, Mawei District, and Changle District) and six non-urban counties at the prefecture level (Minhou County, Lianjiang County, Luoyuan County, Minqing County, Yongtai County, and Fuqing City). The population data of the counties (cities) and prefectures in Fuzhou were obtained from the Statistical Yearbook of the Fuzhou Bureau of Statistics.

\subsection{Research objects}


Inclusion criteria: ${ }$ Patients who were diagnosed by psychiatric practitioners based on the 10th revised "International Statistical Classification of Diseases and Related Health Problems" (ICD-10) and included in the National Management of Severe Mental Disorders; $₫ A l l$ registered patients who provided informed consent and focus was on home management. Exclusion criteria: Patients who refused to register for management and those lost during follow-up for three consecutive years or were confirmed dead. Psychiatric staff at districts, counties, and prefectures in Fuzhou regularly conducted information verification and quality control management on the disease data of SMD patients to ensure reliability and reduce the occurrence of deviations.

\subsection{Observation Indicators}

The observation indicators were: $\otimes$ Prevalence at time point (\%o) (the number of new and old cases of SMD in a specific population at a certain time/total population at that time $\times 1000 \%$ ). $₫$ Medication rate (\%)(number of SMD patients taking medication/number of SMD patients $\times 100 \%$. SMD patients taking medication are registered as taking medications, including regular medication and intermittent medication by mental health staff. $\otimes$ Regular medication rate (\%)(number of SMD patients regularly taking medication/number of registered SMD patients $\times 100 \%$. SMD patients s regularly taking medication are those registered as regular medications by mental health practitioners. $₫$ Management rate (\%) (the number of registered management/total number of SMD patients. SMD management refers to the detailed assessment of SMD patients. Continuous lock-in, unstable disease conditions, long-term continuous medication, mental retardation (may be accompanied by mental disorders), and other harmful behaviors (self-injury, attempted suicide, etc.) are associated with SMD patients. The medical staff of the community health service centre regularly assessed the regularity of medication and injury behaviors of SMD patients.

\subsection{Statistical analysis}

Excel 2019 software was used to organize and summarize data. ArcMap10.2 software was used to draw grade maps. SPSS20.0 software was used for data analysis, calculating prevalence and composition ratio, and descriptive analysis of regional and patient demographic characteristics. The linear trend chisquare test was used to analyze the correlation between month and the prevalence of SMD patients in Fuzhou. $\chi 2$ test was used to compare the qualitative data between groups. The test level was two-sided at $\mathrm{a}=0.05$.

\section{Results}

\subsection{Distribution characteristics of SMD types in Fuzhou}

A total of 30,362 registered SMD patients were identified in Fuzhou City (prevalence rate, 4.17\%o). Schizophrenia accounted for the highest number $(26204,86.31 \%)$. The number of patients, time-point prevalence and composition of other diseases are shown in Table 1. The distribution characteristics of various SMD types are shown in Figure 1. 
Table 1 Prevalence of Severe Mental Disorders in Fuzhou City

\begin{tabular}{llll} 
Diseases types & Cases(person) & $\begin{array}{l}\text { Time point prevalence } \\
(\% \circ)\end{array}$ & $\begin{array}{l}\text { Composition ratio } \\
\text { षQ }\end{array}$ \\
\hline Schizophrenia & 26204 & 3.60 & 86.31 \\
\hline $\begin{array}{l}\text { Mental retardation (with mental } \\
\text { disorders) }\end{array}$ & 2121 & 0.29 & 6.98 \\
\hline Bbipolar disorder & 1292 & 0.18 & 4.26 \\
\hline Mental disorders caused by epilepsy & 530 & 0.07 & 1.75 \\
\hline Schizoaffective psychosis & 168 & 0.02 & 0.55 \\
\hline Paranoid psychosis & 47 & 0.01 & 0.15 \\
\hline Total & 30362 & 4.17 & 100
\end{tabular}

\subsection{The "Three Distributions" of SMD in Fuzhou}

\subsubsection{Population distribution}

A total of 30,362 registered SMD patients were identified in Fuzhou. The specific distribution is shown in Table 2.

Table 2 Demographic data of patients with severe mental disorders in Fuzhou 


\begin{tabular}{|c|c|c|}
\hline \multicolumn{3}{|l|}{ Gender } \\
\hline Male & 16633 & 54.78 \\
\hline Female & 13729 & 45.22 \\
\hline \multicolumn{3}{|l|}{ Age } \\
\hline Under 18 & 377 & 1.24 \\
\hline 8 (inclusive)-44 years old & 13778 & 45.38 \\
\hline $45-59$ years old & 10248 & 33.75 \\
\hline $60-64$ years old & 2456 & 8.09 \\
\hline 65 years old and above & 3503 & 11.54 \\
\hline \multicolumn{3}{|l|}{ Education level } \\
\hline Elementary school and below & 14593 & 48.06 \\
\hline Junior high school or technical secondary school & 12841 & 42.29 \\
\hline University and above & 646 & 2.13 \\
\hline Unknown & 1855 & 6.11 \\
\hline \multicolumn{3}{|l|}{ Marital status } \\
\hline Unmarried & 11582 & 38.15 \\
\hline Married & 15155 & 49.91 \\
\hline Widowed & 746 & 2.46 \\
\hline Divorce & 1531 & 5.04 \\
\hline Unspecified marital status & 1348 & 4.44 \\
\hline \multicolumn{3}{|l|}{ Family history of severe mental disorders } \\
\hline YES & 1434 & 4.71 \\
\hline NO & 27058 & 89.12 \\
\hline Unknown & 1873 & 6.17 \\
\hline \multicolumn{3}{|l|}{ Economic status } \\
\hline Poor & 16796 & 55.32 \\
\hline Non-poverty & 12792 & 42.13 \\
\hline Unknown & 774 & 2.55 \\
\hline
\end{tabular}




\begin{tabular}{lll} 
Profession & 588 & 1.94 \\
\hline On-duty workers & 61 & 0.20 \\
\hline On-the-job manager & 9177 & 30.23 \\
\hline Farmer & 7644 & 25.18 \\
\hline Laid-off or unemployed & 177 & 0.58 \\
\hline School student & 636 & 2.09 \\
\hline Retirement & 285 & 0.94 \\
\hline Professional skill worker & 7274 & 23.96 \\
\hline Other Unknown area & 4520 & 14.89 \\
\hline Unknown & 15949 & 52.53 \\
\hline Area & & \\
\hline Urban area & 14413 & 47.47
\end{tabular}

\subsubsection{Local distribution}

The prevalence of SMD was lower in urban areas than in non-urban areas. Minqing County had the highest prevalence rate, followed by Yongtai County, while Mawei District had the lowest prevalence rate. SMD prevalence was significantly different among various Fuzhou regions $(P<0.05)($ Table 3 and Figure 2).

Table 3 The prevalence of severe mental disorders in various districts and counties in Fuzhou 


\begin{tabular}{llllll} 
Region & $\begin{array}{l}\text { Permanent population } \\
(10,000 \text { people) }\end{array}$ & $\begin{array}{l}\text { Confirmed } \\
\text { cases (person) }\end{array}$ & $\begin{array}{l}\text { Time point } \\
\text { prevalence (\%o) }\end{array}$ & $\chi^{2}$ value & $\begin{array}{c}P \\
\text { value }\end{array}$ \\
\hline Gulou District & 74.0 & 2974 & 4.02 & 239.722 & 0.001 \\
\hline Taijiang District & 48.6 & 1947 & 4.01 & \\
\hline CangshanDistrict & 83.6 & 3379 & 4.04 & \\
\hline Mawei District & 26.2 & 996 & 3.80 \\
\hline Jin'an District & 87.7 & 3457 & 3.94 \\
\hline Changle District & 73.9 & 3196 & 4.32 \\
\hline Minhou County & 72.5 & 2847 & 3.93 & \\
\hline Lianjiang County & 59.3 & 2462 & 4.15 & \\
\hline Luoyuan County & 21.2 & 1008 & 4.75 \\
\hline Minqing County & 24.0 & 1389 & 5.79 & \\
\hline Yongtai County & 25.4 & 1226 & 4.83 & \\
\hline Fuqing City & 131.6 & 5481 & 4.16 &
\end{tabular}

\subsubsection{Time Distribution}

The chi-square test showed a linear trend between the monthly and the time-point prevalence of SMD, with a statistically significant difference $(P<0.05)$. SMD prevalence showed a monthly linear increasing trend (Figure 3 and Table 4).

Table 4 Prevalence of Severe Mental Disorders in Fuzhou City by Month 
Month Total number (person) Time point prevalence (\%o) $\quad Z$ value $\quad P$ value

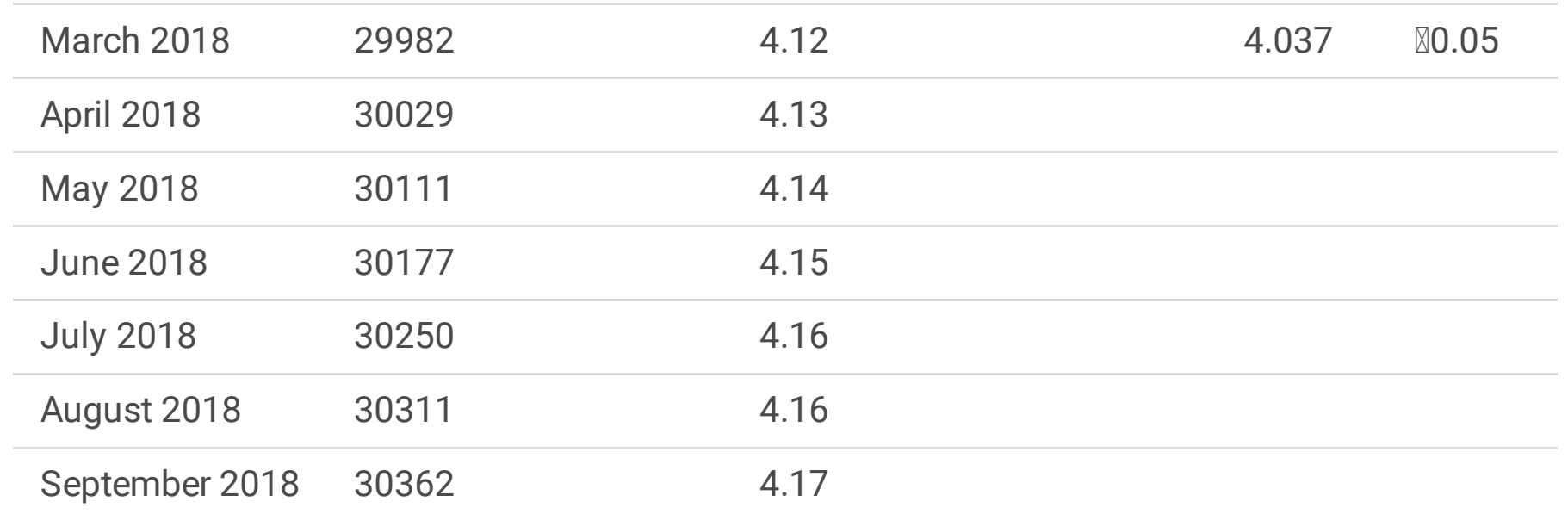

\subsection{Medications for SMD patients in Fuzhou}

A total of 22,989 of 30,362 SMD patients were taking medication (75.72\%). A total of 17,509 were taking the medication regularly $(57.67 \%)$. The rate of taking medication and the rate of regular-taking was significantly higher in urban areas than in non-urban areas $(P<0.05)$ (Table 5 and Table 6).

All SMD types were found in urban areas. Medication rate and regular-taking rate were highest among patients with mental disorders caused by epilepsy ( $91.60 \%$ and $80.40 \%$, respectively) with statistically significant differences $(P<0.05)($ Table 7 and Table 8$)$.

Table 5 Drugs taken by patients with severe mental disorders in Fuzhou

\begin{tabular}{llllll} 
Area & $\begin{array}{l}\text { Number of registered } \\
\text { patients (persons) }\end{array}$ & $\begin{array}{l}\text { Number of } \\
\text { medications (persons) }\end{array}$ & $\begin{array}{l}\text { Medication } \\
\text { rate (\%) }\end{array}$ & $\chi^{2}$ value & $\begin{array}{l}P \\
\text { value }\end{array}$ \\
\hline $\begin{array}{l}\text { Urban } \\
\text { area }\end{array}$ & 15949 & 12579 & 78.87 & 181.749 & 0.001 \\
\hline $\begin{array}{l}\text { Non- } \\
\text { urban }\end{array}$ & 14413 & 10410 & 72.23 & & \\
\hline
\end{tabular}

Table 6 Regular medication status of patients with severe mental disorders in Fuzhou 

patients (persons)
Area Number of registered
Number of regular medications (person)
Regular

Urban 15949 area

Non- 14413 urban
10486

7023 medication rate $\quad \chi^{2}$ value (\%)
65.75

898.427
$P$ value

48.73

Table 7 Drugs taken by patients with various types of severe mental disorders in Fuzhou
Classification

Number of medications (persons)
Medication rate $(\%)$ $\chi^{2}$ value $\stackrel{P}{\text { value }}$

\section{Schizophrenia}

Urban area

13423

10683

79.59

105.523

0.001

Non-urban

12781

9489

74.24

Paranoid psychosis

Urban area

17

13

76.47

4.821

$₫ 0.05$

Non-urban

30

13

43.33

Schizoaffective psychosis

Urban area

71

55

77.46

4.625

$\otimes 0.05$

Non-urban

97

60

79.38

bipolar disorder

Urban area

667

507

76.01

16.003

0.001

Non-urban

625

412

65.92

Mental disorders caused by epilepsy

Urban area 250

229

91.6

37.788

0.001

Non-urban

280

197

70.36

Mental retardation (with mental disorders)

Urban area

Non-urban
1521

600
1093

212
71.86

35.33
242.524

0.001 
Table 8 Regular medications of patients with various types of severe mental disorders in Fuzhou

$\begin{array}{llllll}\text { Classification } & \begin{array}{l}\text { Number of } \\ \text { registered patients } \\ \text { (persons) }\end{array} & \begin{array}{l}\text { Number of regular } \\ \text { medications } \\ \text { (persons) }\end{array} & \begin{array}{l}\text { Regular } \\ \text { Medication } \\ \text { rate }(\%)\end{array}\end{array} \quad \chi^{2}$ value $\quad \begin{aligned} & P \\ & \text { value }\end{aligned}$

Schizophrenia

Urban area

13423

9020

67.2

718.622
प
0.001

\begin{tabular}{|c|c|c|c|c|c|}
\hline Non-urban & 12781 & 6508 & 50.92 & & \\
\hline \multicolumn{6}{|c|}{ Paranoid psychosis } \\
\hline Urban area & 17 & 11 & 64.71 & 4.321 & $\nabla 0.05$ \\
\hline Non-urban & 30 & 10 & 33.33 & & \\
\hline
\end{tabular}

Schizoaffective psychosis

$\begin{array}{llllll}\text { Urban area } & 71 & 48 & 67.61 & 6.12 & \otimes 0.05 \\ \text { Non-urban } & 97 & 47 & 48.45 & & \end{array}$

bipolar disorder

$\begin{array}{llllll}\text { Urban area } & 667 & 434 & 65.07 & 60.445 & \square \\ & & & & 0.001\end{array}$

$\begin{array}{llll}\text { Non-urban } & 625 & 272 & 43.52\end{array}$

Mental disorders caused by epilepsy

$\begin{array}{llllll}\text { Urban area } & 250 & 201 & 80.4 & 73.938 & \square \\ & & & 0.001\end{array}$

$\begin{array}{lll}\text { Non-urban } \quad 280 & 123 & 43.93\end{array}$

Mental retardation (with mental disorders)

$\begin{array}{llllll}\text { Urban area } & 1521 & 772 & 50.66 & 292.117 & \square \\ & & & & 0.001\end{array}$

$\begin{array}{lll}\text { Non-urban } \quad 600 & 63 & 10.5\end{array}$

\subsection{Management of SMD patients in Fuzhou}

A total of 3065 of 30,362 SMD patients were registered for management $(10.09 \%)(2244(16.37 \%)$ in urban areas and 821 in non-urban areas (6.04\%)) The management rate was significantly higher in urban areas than in non-urban areas $(P<0.05)($ Table 9$)$. 
Table 9 Management of patients with severe mental disorders in Fuzhou

\begin{tabular}{llllll} 
Area & $\begin{array}{l}\text { Management } \\
\text { group }\end{array}$ & $\begin{array}{l}\text { Non-management } \\
\text { group }\end{array}$ & $\begin{array}{l}\text { Management rate } \\
(\%)\end{array}$ & $\chi^{2}$ value & $\begin{array}{l}P \\
\text { value }\end{array}$ \\
\hline $\begin{array}{l}\text { Urban } \\
\text { area }\end{array}$ & 2244 & 13705 & 16.37 & 584.921 & 0 \\
\hline $\begin{array}{l}\text { Non- } \\
\text { urban }\end{array}$ & 821 & 13592 & 6.001 & \\
\hline
\end{tabular}

\section{Discussion}

\subsection{Schizophrenia requires comprehensive prevention and control in Fuzhou}

Herein, of 30,362 registered SMD patients, schizophrenia had the highest number ( $86.31 \%)$, followed by mental retardation (with mental disorders) $(6.98 \%)$, while paranoid psychosis had the least $(0.15 \%)$, consistent with research results of many scholars, such as Liao Zhixian [11]. Therefore, severe Schizophrenia and mental retardation (associated with mental disorders) are key diseases in Fuzhou that need comprehensive prevention

Schizophrenia is a chronic mental illness with the most severe symptoms and is the most difficult to treat. Schizophrenia patients have rigid eyes, are sensitive and suspicious, have unreasonable tension, fear, psychological changes, are easily irritable, have low self-care ability, are antisocial, etc. Severe schizophrenia may lead to suicide or other injuries $\left[{ }^{[2]}\right.$. Most studies ${ }^{[12]}$ have shown that women, with high education levels, married, late onset, acute or subacute onset, cheerful personality before the disease, good interpersonal relations, and good social mechanisms and functions before the disease. Negative symptoms are diagnosed as the main clinical phase. Strong family social institutions and functions, timely treatment, systematic, and high compliance can positively enhance disease treatment. Moreover, the above are considered as evaluation indexes for poor treatment effects.

Presently, typical or atypical antipsychotics are mainly used to treat SMD. Meanwhile, targeted psychological care can effectively stabilize the patient's mood, increase emotional experience and expression, reduce psychological pressure, and effectively improve the patient's psychological state and reduce the disease burden. Many experts and scholars, including Fan ChiHsuan[ ${ }^{[3]}$, have shown that support from family and other communities can effectively reduce the severity of schizophrenia symptoms in various patients. Therefore, the patient's family and community should improve their relationship with the patient to enhance monitoring and management of the symptoms of SMD patients. Furthermore, schizophrenia in some families has been solved through improved social relationships.

About $60 \%$ of SMD cases can be treated and relieved via socialization due to the continuous development and technological advancement of modern therapeutics in China in recent years. 


\subsection{Comprehensive prevention and control of SMD in Fuzhou should focus on poor and patients with low educational backgrounds}

This study showed that more men suffer from SMD than women in Fuzhou, consistent with Alejandra Caqueo-Urízar and other scholars[ $\left[{ }^{14]}\right.$, suggesting that it may be related to mental stress in daily life and work environment.

Most SMD patients are 18 (inclusive)-44 years old (45.38\%) and 45 (inclusive)-59 years old (33.75\%). Married people have SMD. These two age groups and married people bear more stress from school, family, work, and life, and face more emergencies, leading to a heavy mental load. Therefore, the Fuzhou Municipal Government should strengthen mental health education among young people and adults and address family mental health problems.

Most SMD patients had a primary education level and below (including semi-illiterate) (54.17\%). Most people with low educational levels have little knowledge of mental health. Therefore, they would not seek medical services when they have mental health problems occur. In contrast, people with a higher level of education know more about mental illness and can seek medical attention as soon as possible. The number of SMD patients is relatively small among people with a high level of education compared with those with low educational level. In addition, people with low educational levels may have difficulty adapting to the rapidly changing society, have poor psychological quality, and are more likely to have a pessimistic mood and behavior. Moreover, people with mental illness are more likely to be unemployed or are under long-term hospitalization, leading to economic difficulties.

Also, Most SMD patients were farmers (30.23\%) and laid-off or unemployed (25.18\%). The proportion of the poor and those below the local poverty line was $55.35 \%$, higher than other cases. Farmers, laid-off workers, and the unemployed have low incomes and poor living standards. They are more likely to have psychological problems when encountered with emergencies. They lose hope in the future and are more likely to be managed by the government.

In summary, most SMD patients have a low educational level. Therefore, the government should pay more attention to these disadvantaged groups, improve the medical insurance system, and sensitize on mental health to reduce the incidence of mental illness. Besides, the relatively high rates of unmarried and divorced patients with SMD indicate that society discriminates against them and is unwilling to interact with them. The government and communities should also spread mental health awareness among the general public to eliminate discrimination.

\subsection{The prevalence of SMD in Fuzhou is lower in urban areas than in non-urban areas and has an increasing trend}

Herein, Minqing County had the highest prevalence rate of SMD (5.79\%o), while Mawei District had the lowest (3.80\%). The time-point prevalence of SMD (4.05\%) was lower in the six urban areas than in the six non-urban areas (4.32\%o). Therefore, SMD is common in non-urban areas because mental health 
awareness is more effective in urban areas than in non-urban areas. Therefore, mental health joint conference system is necessary for the districts, counties and sub-districts of Fuzhou Health promotion links. Besides, the reporting system should be improved to increase the consciousness of Fuzhou residents to seek medical treatment.

Furthermore, SMD prevalence in Fuzhou City increased from March 2018 to September 2018. The prevalence rate also slightly increased in these months because SMD is a longer course disease. SMD often recurs, is more difficult to cure, has a small migration, and the patient's residence is relatively fixed. Therefore, community and hospital staff should conduct regular-follow up, assess the medication status of SMD patients discharged from the hospital, and educate family members on the importance of ensuring the patient takes medication. Meanwhile, public awareness of SMD should be further strengthened to prevent and reduce SMD cases.

\subsection{The medication and management rates of SMD patients in Fuzhou are higher in urban areas than in non-urban areas}

WHO defines medication compliance as the degree of consistency between an individual's medication use and the doctor's prescription[ ${ }^{15}$. Most scholars have focused on the medication compliance of SMD patients as early as the 1970s. Medication treatment is the most effective method for improving SMD. Besides, the government has issued corresponding subsidy policies, greatly reduce the cost of treating SMD patients, burden, preventing patients' irregular visits to doctors and random medication, reducing disease fluctuations, attracting patients into community management $\left[{ }^{16-17}\right]$.

Herein, the taking-rate and the regular taking-rate of registered SMD patients were $75.72 \%$ and $57.67 \%$, respectively. Presently, the national taking-rate and regular taking-rate among SMD patients are $81.30 \%$ and is $41.78 \%$, respectively. Therefore, the rate of taking drugs is significantly lower than that of the current national level, while the rate of regular-taking is higher than that of the national level[ ${ }^{[8]}$. Furthermore, the medication and regular medication rates were significantly different between urban and non-urban areas in Fuzhou. Based on different SMD types, the medication and regular medication rates were significantly higher in the six urban areas than in the non-urban area. This could be because urban area has better medical resources and talent facilities than the non-urban areas, guaranteeing quality medical treatment. Moreover, community rehabilitation staff in urban areas are well-trained and can supervise SMD patients better than in non-urban areas. Therefore, patients in urban areas have access to more standardized management. Also, patients in urban areas have a higher education level, better ways of obtaining disease-related knowledge through multiple channels, and higher medication compliance than patients in non-urban areas[ ${ }^{19]}$. Herein, the rate of medication and regular medication was highest for mental disorders caused by epilepsy, consistent with the results of Nesvåg Ragnar and other

scholars [20], suggesting that there are positive symptoms of schizophrenia, such as hallucinations. Some patients who have delusions believe that they are being persecuted and have poor medication compliance. The more serious the positive symptoms before treatment, the worse the medication compliance. 
Among patients with recurrent schizophrenia for the first time, $75 \%$ of patients maintain effective treatment through drugs and clinical treatments. However, the rate of patients with recurrent episodes or severe deterioration could be higher in the future, and antipsychotic drugs can prevent its recurrence. Population and sociological factors, disease-related factors, psychological factors, drug-related factors, and other social support affect medication compliance in schizophrenia patients. Therefore, medical staff should assess the medication compliance of patients with mental disorders and the main influencing factors of non-compliance and offer individualized intervention strategies.

The management rate of SMD patients in Fuzhou was significantly lower (10.09\%) than the current national management rate $(82.69 \%)$. Also, the management rate was significantly higher in urban areas than in non-urban areas, possibly because the management system is more effective in urban areas than in non-urban areas.

Moreover, patients in non-urban areas often go out for work, making it difficult for community rehabilitation workers and medical staff to manage them in a unified manner. Therefore, the government should strengthen the work quality of non-urban psychiatrists and improve the follow-up work in the community, targeted training of medical staff and family care management $\left[{ }^{21]}\right.$ to enhance the management rate of registered patients.

\section{Conclusion}

Schizophrenia accounts for the highest proportion of all SMD in Fuzhou and requires comprehensive prevention. Mental retardation (may be accompanied by mental disorders) also accounts for a high proportion of SMD. Therefore, the government should focus on Schizophrenia and Mental retardation, provide support to families, and formulate targeted treatment programs. However, other SMD types should not be completely ignored. Most SMD patients in Fuzhou have a low educational level, are poor, and are married. Therefore, the government should focus on these disadvantaged groups and strengthen treatment. The government should also improve the medical insurance system, establish a community rehabilitation system, and create a suitable community environment for patient rehabilitation. The medication, regular medication, and management rates of SMD patients in Fuzhou are higher in urban areas than in non-urban areas. However, the rates are lower than those of the national level. Therefore, the government should enhance mental health prevention and control work in Fuzhou, improve health institutions to reduce the prevalence of SMD, and thus protecting people's health.

\section{Declarations}

\section{Consent for publication}

All participants provided informed consent, including consent to publish scientific manuscripts based on collected data, in order to participate in the study.

\section{Availability of data and materials}


The datasets generated and/or analysed during the current study are not publicly available due to individual privacy but are available in summary/group level form from the corresponding author on reasonable request.

\section{Acknowledgements}

The first authors want to thank all participants.

\section{CRediT authorship contribution statement}

Zheng Fuhao: Investigation, Writing and editing; Lin Yawen: Methodology, Investigation. Wei Qinfei: Investigation and data analysis. Zeng Zhaonan: Investigation and data analysis. Xiong Duanhua: Investigation. Si-Ying Wu: Conceptualization, Writing - review \& editing.

\section{Funding}

This work was supported by grant from 2018 Fujian Provincial Department of Finance (Fujian Finance $\triangle 2018 \otimes 710)$ and 2016 Fujian Medical initial research project (2016QH126) and 2020 Fujian Medical initial research project (2020QH1148).

\section{Ethics approval and consent to participate}

All participants joined voluntarily and signed a consent form before participation. The investigation passed the ethics committee of Fujian Provincial Hospital『K2021-04-049『.

\section{Competing interests}

The authors declare that they have no competing interests.

\section{References}

1. Hartmann Tegan E. et al. Associations between exercise, inflammation and symptom severity in those with mental health disorders[J]. Cytokine, 2021, 146

2. Dou L, Hu L, Zhang N, et al. Factors Associated with Medication Adherence Among Patients with Severe Mental Disorders in China: A Propensity Score Matching Study[J]. Patient Preference and Adherence, 2020, 31(14): 1329-1339.

3. Rehm J, Shield KD. Global Burden of Disease and the Impact of Mental and Addictive Disorders[J]. Curr Psychiatry Rep, 2019, 21(2): 10.

4. Xu J, Wang J, Wimo A, et al. The economic burden of mental disorders in China, 2005-2013: implications for health policy[J]. BMC psychiatry, 2016, 16: 137.

5. Merchant R, Torous J, Rodriguez-Villa E, et al. Digital technology for management of severe mental disorders in low-income and middle-income countries[J]. Current opinion in psychiatry, 2020, 33(5): 501-507. 
6. Liu NH, Daumit GL, Dua T, et al. Excess mortality in persons with severe mental disorders: a multilevel intervention framework and priorities for clinical practice, policy and research agendas[J]. World psychiatry: official journal of the World Psychiatric Association (WPA), 2017, 16(1): 30-40.

7. Blasco-Fontecilla $\mathrm{H}$. Clinical utility of pharmacogenetic testing in children and adolescents with severe mental disorders[J]. Journal of neural transmission (Vienna, Austria: 1996), 2019, 126(1): 101107.

8. EstradaFernández María Eugenia et al. The impact of community care: Burden and quality of life of the informal caregivers of patients with severe mental disorder[J]. Journal of community psychology, 2021.

9. Li Yaxi et al. Excess mortality among patients with severe mental disorders and effects of community-based mental healthcare: a community-based prospective study in Sichuan, China.[J]. BJPsych open, 2021, 7(3) : e84-e84.

10. Chen Wen Yin et al. Excess mortality and risk factors for mortality among patients with severe mental disorders receiving home care case management[J]. Nordic Journal of Psychiatry, 2021, 75(2) : 109-117.

11. Chen R, Li NX, Liu X. Study on the equity of medical services utilization for elderly enrolled in different basic social medical insurance systems in an underdeveloped city of Southwest China[J]. Int J Equity Health, 2018, 17(1): 54.

12. Chen S, Liu Y, Liu D, et al. The difference of social cognitive and neurocognitive performance between patients with schizophrenia at different stages and influencing factors[J]. Schizophrenia Research Cognition, 2021, 24: 100195.

13. Fan $\mathrm{CH}$, Hsu SC, Hsiao FH, et al. The Association of Social Support and Symptomatic Remission among Community-Dwelling Schizophrenia Patients: A Cross-Sectional Study[J]. International Journal of Environmental Research and Public Health, 2021, 18(8): 3977-3977.

14. Caqueo-Urízar A, Fond G, Urzúa A, et al. Gender differences in schizophrenia: A multicentric study from three Latin-America countries[J]. Psychiatry Research, 2018, 266: 65-71.

15. 15[1]] Farooq S, Choudry A. Adherence to medication in the community: audit cycle of interventions to improve the assessment of adherence[J]. BJPsych Bull, 2017, 41(1): 41-44.

16. Gebeyehu Daniel Ayelegne and Mulatie Missaye. Risky sexual behavior and its associated factors among patients with severe mental disorder in University of Gondar Comprehensive Specialized Hospital, 2018.[J]. BMC psychiatry, 2021, 21(1) : 51-51.

17. Li Ying and Ma Hongmei. Interorganisational cooperation and its effects on community rehabilitation for people with severe mental disorders in Beijing, China: A case study.[J]. Health \& social care in the community, 2021, 29(1) : 154-163.

18. Cavalera Cesare et al. Substance use disorders and violent behaviour in patients with severe mental disorders: A prospective, multicentre study[J]. Australian \& New Zealand Journal of Psychiatry, 2020, 54(12) : 1212-1223. 
19. Barfar E, Sharifi V, Amini H, et al. Cost-effectiveness Analysis of an Aftercare Service vs Treatment-AsUsual for Patients with Severe Mental Disorders[J]. The journal of mental health policy and economics, 2017, 20(3): 101-110.

20. Nesvåg R, Bramness JG, Handal M, et al. The incidence, psychiatric co-morbidity and pharmacological treatment of severe mental disorders in children and adolescents[J]. European psychiatry: the journal of the Association of European Psychiatrists, 2018, 49: 16-22.

21. Chen WY, Huang SJ, Chang CK, et al. Excess mortality and risk factors for mortality among patients with severe mental disorders receiving home care case management[J]. Nordic Journal of Psychiatry, 2021, 75(2): 109-117.

\section{Figures}

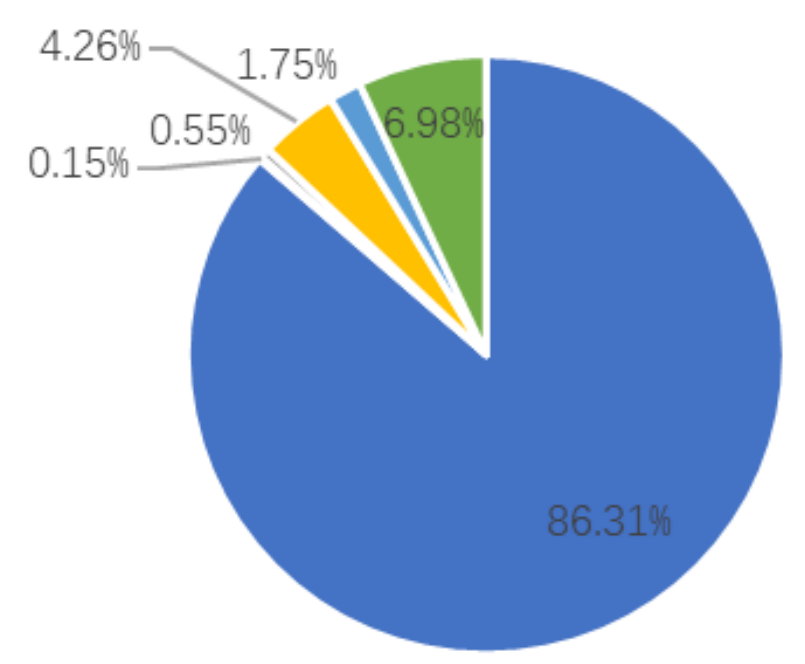

- Schizophrenia

- Schizoaffective psychosis

- Mental disorders caused by epilepsy
- Paranoid psychosis

- Bipolar disorder

- Mental retardation (with mental disorders)

Figure 1

Distribution characteristics of SMD types in Fuzhou 


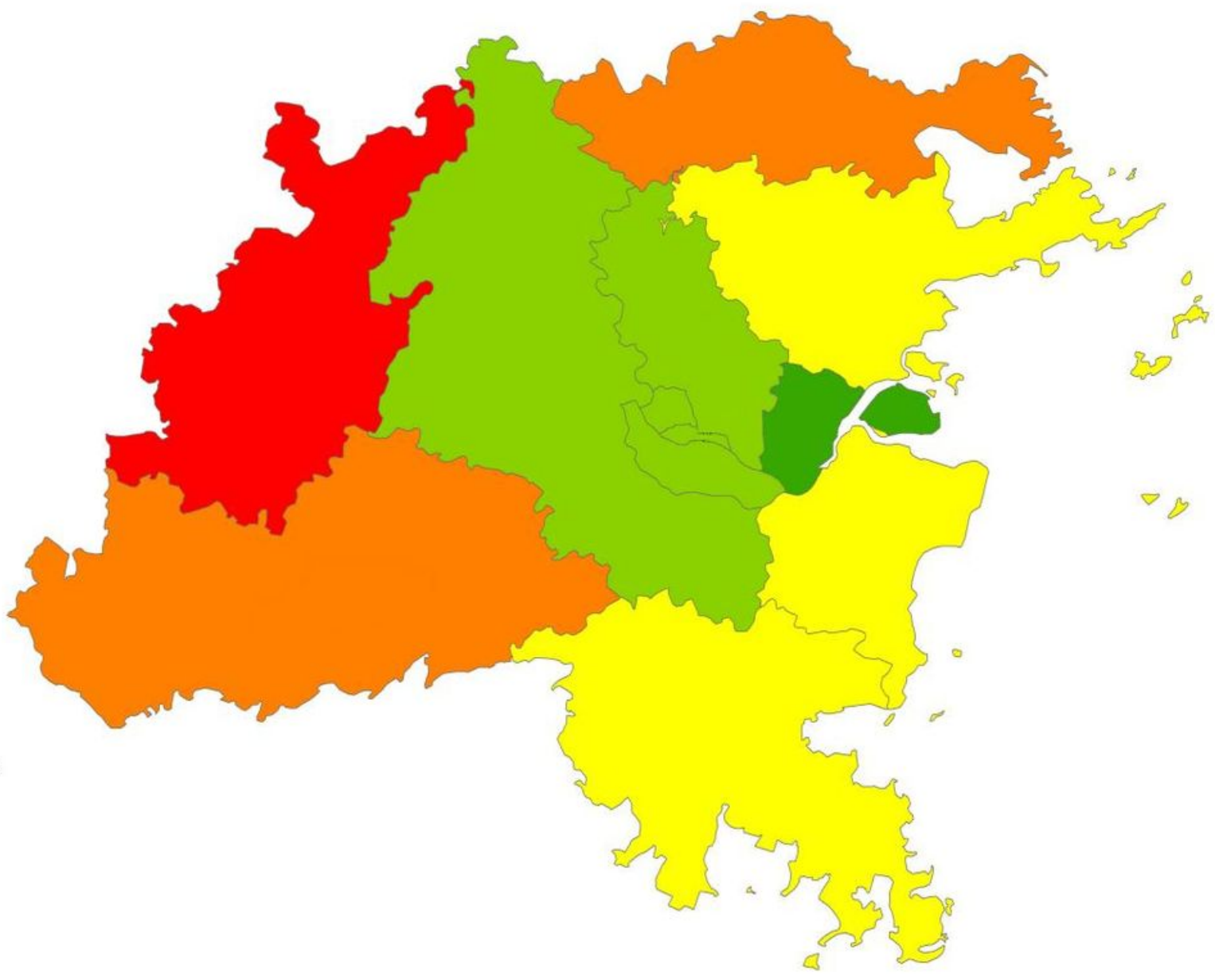

Figure 2

Grade map of the number of patients with severe mental disorders in each district and county of Fuzhou 


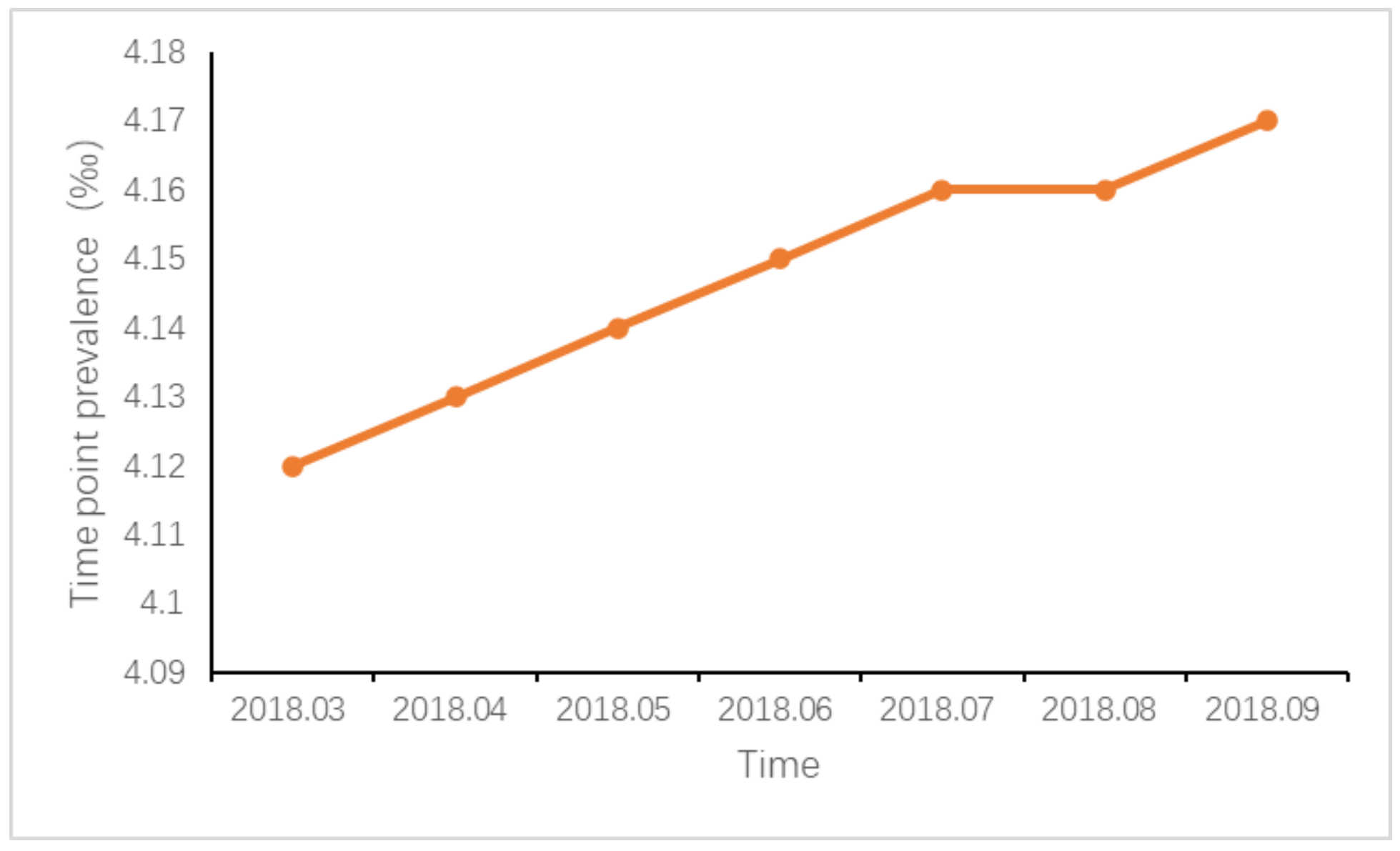

Figure 3

Time distribution of patients with severe mental disorders in Fuzhou 